\title{
Das Widerrufsrecht bei Kaufverträgen im Spannungsverhältnis von Opportunismus und Effektivität
}

Die Rückabwicklung nach Widerruf unter besonderer Berücksichtigung der Verhaltensökonomik

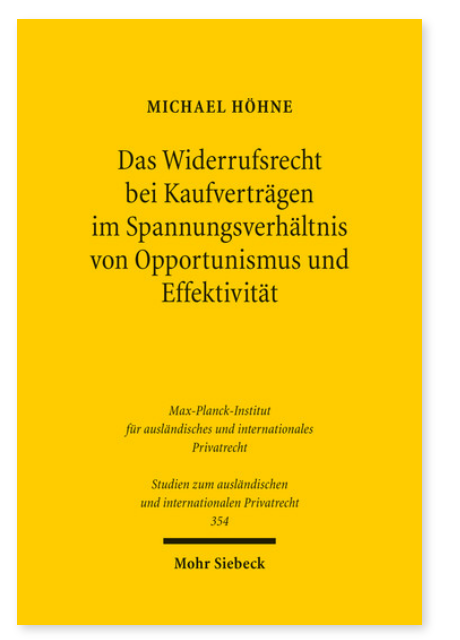

2016. XXVII, 289 Seiten. StudIPR 354

ISBN 978-3-16-154512-2

DOI 10.1628/978-3-16-154512-2

eBook PDF 74,00€

ISBN 978-3-16-154511-5

fadengeheftete Broschur 74,00€
Die typisierende Ausgestaltung des Widerrufsrechts bei Kaufverträgen im Rahmen von besonderen Vertriebsformen begünstigt eine zweckwidrig-opportunistische Ausnutzung dieses Verbraucherschutzinstruments durch die Verbraucher. Freilich müssen Begrenzungen opportunistischen Verhaltens mit der Effektivität des Widerrufsrechts in Einklang gebracht werden. In diesem Spannungsverhältnis müssen auch Erkenntnisse der Verhaltensökonomik berücksichtigt werden. Viele Verbraucher unterliegen Verhaltensanomalien, die die Effektivität des Widerrufsrechts generell verringern, sodass Begrenzungen opportunistischen Verhaltens noch behutsamer ausgestaltet werden müssen.

Michael Höhne analysiert die Rückabwicklung nach Widerruf im Lichte des Spannungsverhältnisses von Opportunismus und Effektivität vor dem Hintergrund der durch die Verbraucherrechterichtlinie notwendig gewordenen Novellierungen im deutschen Recht. Hierbei konkretisiert er das geltende Recht und bereitet einen zukünftigen Diskurs vor.

Michael Höhne Geboren 1987; Studium der Rechtswissenschaft an der Johann Wolfgang Goethe-Universität Frankfurt am Main; 2012 Erste Juristische Staatsprüfung; 2013-16 wissenschaftlicher Mitarbeiter am Institut für Internationales und Europäisches Privatrecht und Rechtsvergleichung an der Johann Wolfgang Goethe-Universität Frankfurt am Main.

Jetzt bestellen:

https://mohrsiebeck.com/buch/das-widerrufsrecht-bei-kaufvertraegen-im-spannungsverhaeltnis-von-opportunismus-undeffektivitaet-9783161545122?no_cache=1

order@mohrsiebeck.com

Telefon: $+49(0) 7071-923-17$

Telefax: $+49(0) 7071-51104$ 